\title{
GENETICS OF COLOUR AND ITS REGULATION DURING DEVELOPMENT IN THE SPIDER ENOPLOGNATHA OVATA (CLERCK) (ARANEAE: THERIDIIDAE)
}

\author{
G. S. OXFORD \\ Department of Biology, University of York, York YOI 5DD, U.K. \\ Received 31.v.83
}

\begin{abstract}
SUMMARY
Breeding experiments have been performed to elucidate the genetics of colour and pattern in Enoplognatha ovata. The three main morphs, lineata, redimita and ovata, appear to be controlled by alleles at one locus. Red pigment in redimita and ovata may be deposited either in the third or fourth instars or at maturity. Patterns appearing early in development are found in both sexes whereas those appearing only at maturity are sex limited to females; males remain plain yellow (lineata). In mature females and some males, ovata is top dominant and lineata bottom recessive. Various genetic models of colour/pattern and its developmental control are explored.
\end{abstract}

\section{INTRODUCTION}

Visible variation in the colours or patterns of spiders is usually continuous. Some species are sexually dimorphic, for example, Diaea dorsata (Fabricus), Misumena vatia (Clerck) and Micrommata virescens (Clerck) (Locket and Millidge, 1951), but only a very small proportion show visible polymorphisms unrelated to sex. As far as I am aware there are no cases in which the genetic control of spider polymorphisms has been fully elucidated (but see Nakahira, 1977; Blanke and Merklinger, 1982).

One widely distributed spider which exhibits discontinuous variation in both pattern and colour is Enoplognatha ovata (Clerck). In this species three major morphs are recognised (Locket and Millidge, 1953). The opisthosoma can be plain yellow (var. lineata Clerck), yellow with two dorsolateral carmine stripes (var. redimita Clerck) or yellow with a solid shield of carmine on the dorsal surface (var. ovata Clerck) (Plates 1a-1c). The striking nature and ubiquity of the polymorphism have resulted in $E$. ovata receiving an unusual amount of attention for a spider (Bristowe, 1931; Geyer, 1967; Tweedie, 1970; Seligy, 1969, 1971; Oxford, 1976, 1983; Hippa and Oksala, 1979, 1981). Knowledge of the underlying genetics of this variation is an essential prerequisite before questions regarding its evolutionary significance can be posed and answers sought.

Although several authors (Geyer, 1967; Tweedie, 1970; Hippa and Oksala, 1979, 1981) have speculated on the genetic control of the polymorphism in $E$. ovata, surprisingly, none have presented breeding data to substantiate their various hypotheses. In this paper, I report data from a number of crosses between the three morphs and explore possible genetic models consistent with the results. 


\section{Methods}

Data on the inheritance of the colour morphs were obtained in two ways. A number of matings were set up in the laboratory between individual males and females from known sources. Virgin females for these crosses were collected in their penultimate instar or earlier from the wild, or isolated from the offspring of previous laboratory matings. Matings which had occurred in the wild were also studied. In these cases the females plus their cocoons were collected from within rolled leaves (Oxford, 1976). The identity of the female parent of the cocoon was therefore certain but of course the male (or males) with which she had mated was unknown. Multiple matings have been observed in laboratory mate-choice experiments but how often they occur in the wild is unknown. Because of the distribution of genotypes in natural populations (see below), the chance is high that a second male would have the same genotype as the first and multiple matings would therefore pass unnoticed.

Crosses in the laboratory were made in plastic sweet jars (capacity 41) containing about $3 \mathrm{~cm}$ of damp Levington's universal compost and a section of $2.5 \mathrm{~cm}$ plastic mesh to act as a web support. Fine nylon gauze sealed the jar tops. Food, in the form of adult fruit flies (Drosophila melanogaster and $D$. funebris), was added through a hole near the neck of the jar, normally plugged with cotton wool. Jars were kept humid and experienced a light: dark cycle of $16: 8$ hours and room temperatures which fluctuated between circa $18^{\circ} \mathrm{C}$ and $24^{\circ} \mathrm{C}$. Cocoons from laboratory crosses or from the wild were isolated with the female parent in $2.5 \times 7.5 \mathrm{~cm}$ glass vials one quarter filled with damp cotton wool. These vials, tightly stoppered with cotton wool, were maintained under the same conditions as the breeding jars. Moving cocoons to vials not only facilitated the handling of young spiders but also prevented infestations by predatory mites which destroyed the eggs.

Prior to 1979 , newly, emerged spiders were placed in individual small glass vials and reared on collembola and Drosophila larvae (Oxford and Pitts, 1981). Mortality was usually very high and was often complete. Matings whose offspring were reared under this regime will be prefixed, in subsequent discussion, by an A. Between 1979 and 1981, the glass vials containing newly emerged young were placed in rearing cages described by Oxford and Pitts (1981). Adult Drosophila and whitefly (Trialeurodes vaporariorum (Westw.)) were added twice weekly to supplement the prey organisms indigenous to the cages. Young were removed from these cages in approximately their fourth instar and subsequently raised on Drosophila larvae in the small vials mentioned above. Matings whose progeny were reared under these conditions will be prefixed by a B. In 1982, young were raised in the rearing cages throughout and were removed and scored either when red pigment had appeared or at maturity, whichever came first. Cages were inspected at weekly intervals. These matings will be designated by the prefix C. Under the latter conditions the time from hatching to the first mature individuals was about three months for males and about four for females. Growth rates varied markedly between individuals and some spiders were still very small even after nine months.

All offspring were scored for morph, sex, stage of maturity, number and positions of the dorsolateral black spots (Oxford, 1976; Hippa and Oksala, 


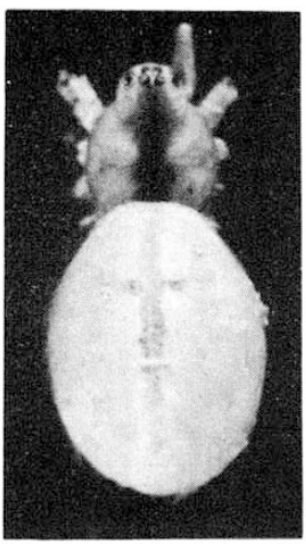

a

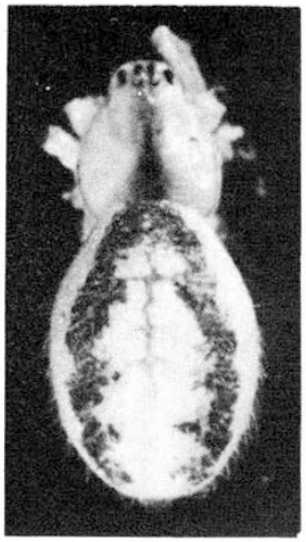

b

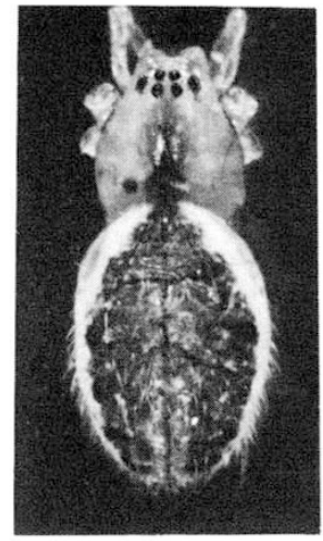

C

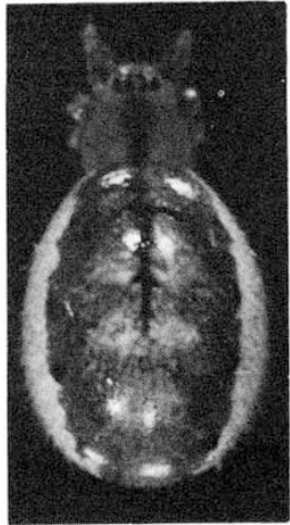

d

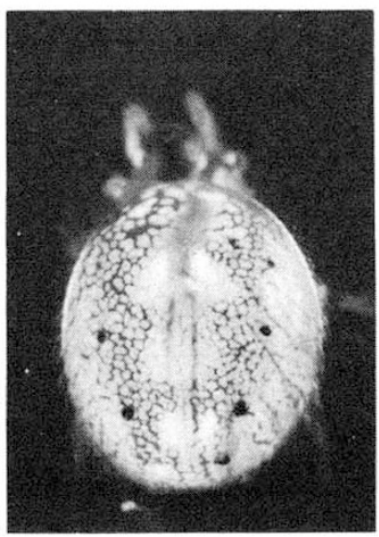

Q

Plate 1. The colour and pattern variation in Enoplognatha ovata. 1a, 1b and 1c illustrate the three main morphs, lineata, redimita and ovata, respectively. 1d shows an ovata individual reared from the egg under laboratory conditions. Note the paler central shield region which produces a pattern intermediate between redimita and a field collected ovata (1c). 1e illustrates the prepattern of ten discernible in the lineata morph. Actual length of the opisthosoma is about $3.5 \mathrm{~mm}$. 
1979) and carapace width, while being held secure in the device described by Oxford (1981). Measurements were made using a binocular microscope fitted with a graticule eyepiece. The majority of spiders, parents and progeny, were preserved in individual air-tight plastic tubes at $-20^{\circ} \mathrm{C}$.

\section{RESULTS}

In this report only the inheritance of colour and pattern will be considered; the genetics of black spotting will be presented elsewhere.

On hatching, all spiders are plain yellow. Individuals may remain yellow throughout their life (lineata) or red pigment may be deposited to give redimita and ovata patterns. Results from the breeding experiments indicate that the deposition of red pigment can occur at two distinct stages in development; either in the third or fourth instars or in the final, mature instar (usually the sixth, but see below). This distinction between the early and late development of redimita and ovata patterns has also been recognised in North American (Seligy, 1971) and Finnish (Hippa and Oksala, 1979) material. For the purposes of this paper, it is convenient to divide broods into (i) those in which red pigment only appears early in development, (ii) those in which it appears only in the final instar and (iii) those in which red pigment is laid down early in some individuals but late in others.

Individuals of broods within category (i) were included in the analysis only if they had reached at least the fourth instar, as judged by carapace width (Seligy, 1971). Spiders in broods included in the other categories were scored only if they were mature (category (ii)) or if they were mature or possessed red pigment (category (iii)). Data from matings falling into these three categories are given in tables 1,2 and 3 . In interpreting the tables it should be noted that in the populations from which parent spiders were removed ovata and redimita are less common than lineata (see also Oxford, 1983).

Consider first those broods in which the final pattern appears in the third or fourth instars. In table 1, the critical mating is B98 between a redimita female and an ovata male. The progeny do not differ significantly from a $1: 1: 2$ ratio (lineata: redimita: ovata) which suggests (a) a regular segregation of characters indicating allelism of the three morphs, (b) the dominance of both ovata and redimita over lineata, (c) the dominance of ovata over redimita and (d) no indications of different morph distributions in the two sexes, suggesting autosomal inheritance. The locus involved in determining the colour/pattern morphs of $E$. ovata will be designated $C$ with alleles $C^{l}$ (lineata), $C^{r}$ (redimita) and $C^{\circ}$ (ovata).

All other matings (table 1), with the exception of B152 and B159, fully support the conclusions drawn above. For example, whenever one parent is ovata then ovata appears in at least half of the progeny. Because of the relative frequencies of ovata and lineata in the wild, the most likely genotype of ovata individuals is $C^{\circ} C^{l}$ and indeed the most frequent phenotypic ratios in progeny from wild-mated ovata females (males were most probably lineata) is 1:1, lineata: ovata (matings A1f, A2f, A3f, A4f, A12f, A14f, B167, B174, B175, B177, B179, C241, C242, C243). In other cases, wild-mated ovata females yielded a 1:1:2 ratio of morphs in their broods similar to that described above for B98 (matings B107, B114, B171). The 
G. S. OXFORD

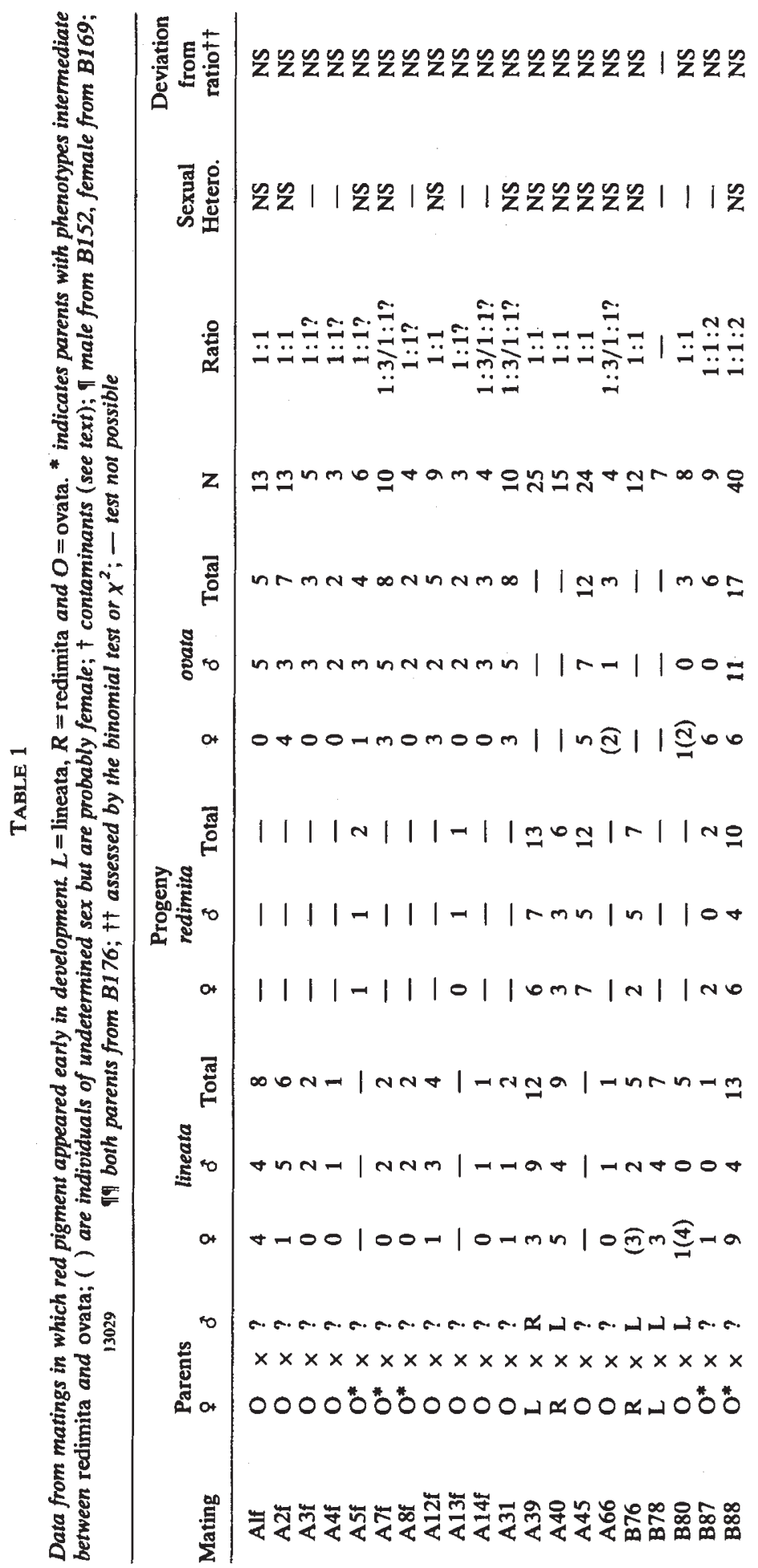




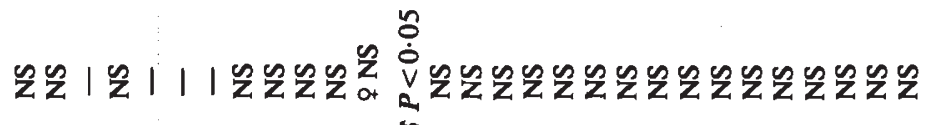
no

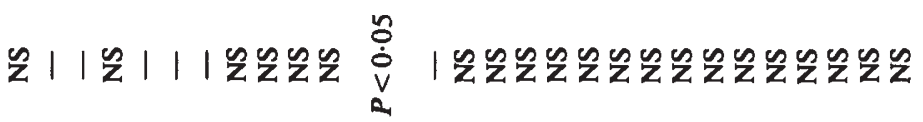
茟

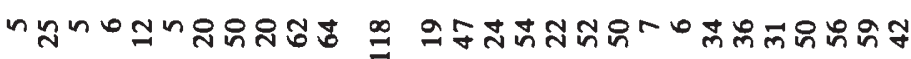

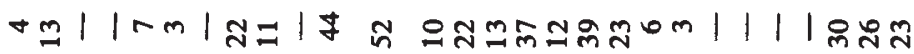

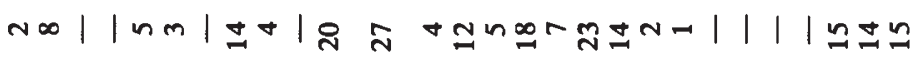
Nu| | no | on I

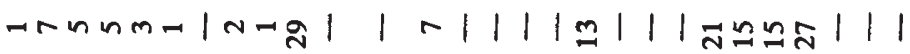

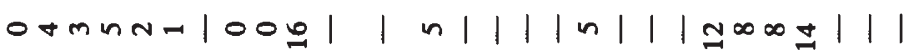

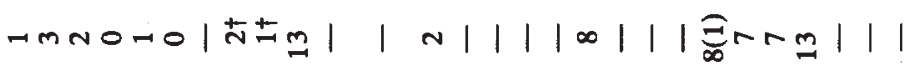

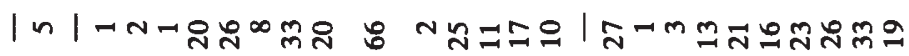

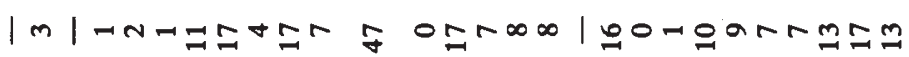

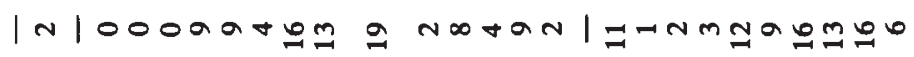

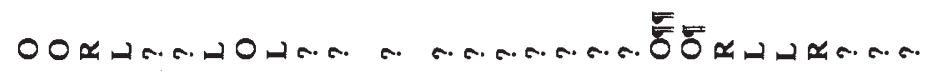
$x \times \times \times \times \times \times \times \times \times \times \times \times \times \times \times \times \times \times \times \times \times x$

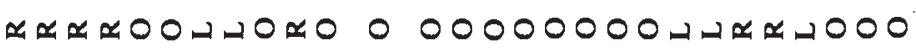

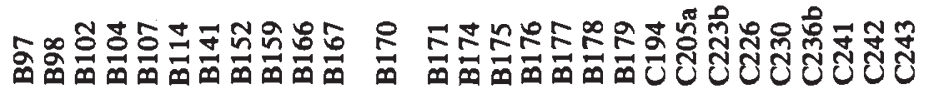


हैं

崖

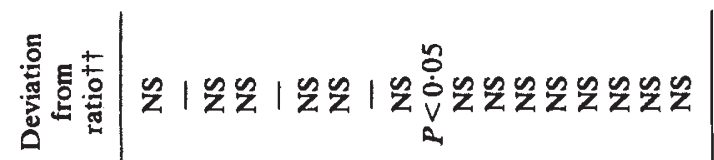

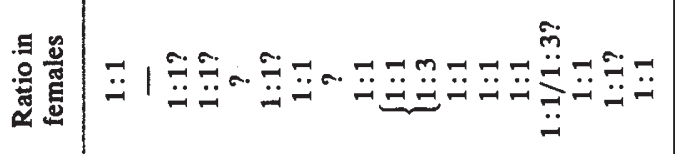

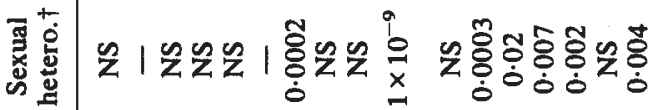

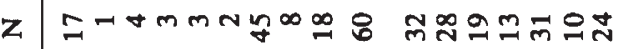

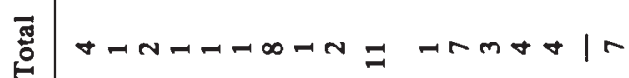

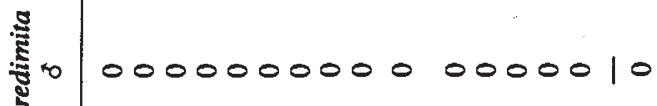

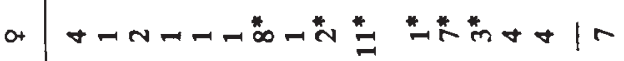

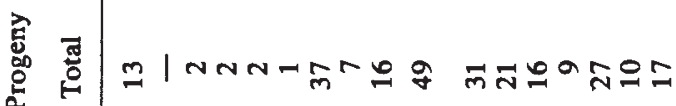
(2)

เู้
है

蕓

3.

हैँ

密.

o g

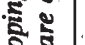

รั้

डิ

$\checkmark 5$

\&े

는 동

恼

*

这

เิ

.5

รั้

点

莎

氝

.

కั ญ

도

20



\begin{tabular}{|c|c|}
\hline 苞苍 & 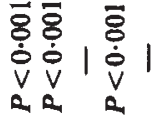 \\
\hline 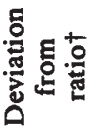 & $\tilde{z} \tilde{z}|\stackrel{n}{z}|$ \\
\hline 胥。 & 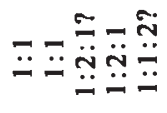 \\
\hline 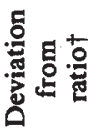 & 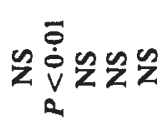 \\
\hline 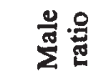 & 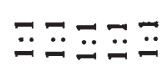 \\
\hline $\mathbf{z}$ & 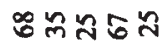 \\
\hline 흄 & $g=11=$ \\
\hline ซี & $\bar{\sim}^{m}||^{0}$ \\
\hline ot & $\widetilde{N}^{\infty}||^{n}$ \\
\hline 焉 & $=r o \infty$ \\
\hline 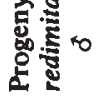 & ootno \\
\hline or & $=\frac{*}{\stackrel{*}{+} \stackrel{*}{+}+\stackrel{*}{*}}$ \\
\hline ฐ્ّ & $\pm \cong \curvearrowleft$ 응 \\
\hline ڤ్ & ニㅡㅇㅠ ${ }^{\infty}$ \\
\hline ot & 烏onan \\
\hline$\stackrel{5}{5}^{+0}$ & 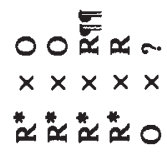 \\
\hline$\underbrace{\infty}$ & 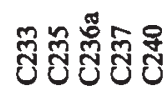 \\
\hline
\end{tabular}


inseminating males were presumably redimita of the genotype $C^{r} C^{l}$, probably the commonest redimita genotype in the populations from which spiders were taken since lineata outnumber redimita. This is also indicated by the results of laboratory matings of redimita $\times$ lineata, all of which yielded a $1: 1$ ratio of these two morphs in their offspring (matings B76, B104, C223b, $\mathrm{C} 226, \mathrm{C} 230, \mathrm{C} 236 \mathrm{~b}-$ see also $\mathrm{B} 98$ ). The autosomal nature of the $C$ locus is further suggested by calculating the heterogeneity in the numbers of each morph separated by sex, for those matings which produced sufficient offspring. In only one case, mating B170, was significant heterogeneity found and this was due entirely to a deviation in males from the expected phenotype ratio of $1: 1$.

Some parents in table 1 are marked with an asterisk to denote that their pattern was intermediate between ovata and redimita. In these individuals the shield (the area between the stripes) is dissected by carmine chevrons and the inter-chevron spaces are either uniform pink or, more usually, contain varying amounts of yellow pigment (Plate 1d). Genetically, intermediates act like ovata. They are allelic to redimita and lineata (matings B87, B88) and dominant to them both (all matings involving intermediates). Indeed, for reasons discussed more fully below, it is very likely that intermediates are ovata in which the full expression of the phenotype is prevented for environmental and/or genetical reasons.

Matings B152 and B159 produced, respectively, two and one individuals of redimita when these would not have been expected from the parents and from the phenotypic ratios in the other progeny. Contamination between cages and between successive broods within a cage is the most likely explanation for these individuals. The cage housing B159 had previously contained the progeny of $\mathrm{B} 102$ and it is not impossible for a redimita from this mating to have remained very small and thus undetected until it was removed with B159 young. In the case of B152, the cage was new but one of the redimita individuals had orange, instead of carmine, stripes which developed in the final instar (a morph described more fully below) and was therefore almost certainly a contaminant.

Turning now to those broods in which the red pigment appeared only in the final instar (table 2), the situation is clearly different from that shown in table 1. The most obvious contrasts are (i) the absence of the ovata morph and (ii) the complete lack of redimita in males, despite all but two matings having a redimita female parent. The ratios of redimita: lineata in the female progeny are just those expected from the results discussed above i.e., most are $1: 1$. The only exception, $\mathrm{B} 168$, deviates from a $1: 1$ ratio $(P<0.05)$ but does not differ significantly from a $3: 1$ ratio, which would not be unexpected. Heterogeneity in the numbers of each morph between the sexes (assessed by Fisher's exact test) is highly significant in all cases in which sufficient numbers of each were scored, and the trend is the same in all other broods as well i.e., an excess of lineata and a deficiency of redimita in males as compared to females.

Matings A93t and A94t involved lineata females collected from a population (Nidderdale $\mathrm{Jb}$-see Oxford, 1976) in which, at the time of sampling, the redimita pattern developed in females only in the last instar and in which males were all lineata-like. Presumably the females of these two matings had mated with lineata-like males which were carrying the redimita allele. This result has also been repeated in cage experiments, both 
in the laboratory and in the field (Oxford, unpublished), in which a number of lineata females plus their cocoons from Nidderdale $\mathrm{Jb}$ were isolated. In both cases, some redimita (late) females were recovered in the offspring but no redimita males. Thus, when the redimita pattern develops in the final instar it does so only in females.

Some redimita females in table 2 are marked with an asterisk. These had orange, instead of carmine, pigment deposited in the stripe region (also noted by Seligy, 1969) and all came from one colony near York (Lock cottage, New Earswick), where they represent 3.4 per cent of the population. The orange stripe condition is clearly heritable and dominant to lineata and may be due to a further allele $C^{\text {ro }}$ (redimita(orange)) at the colour locus or to a dominant modifier at a different locus.

Finally, consider the broods in which red pigment is deposited early in some individuals but late in others (table 3). Mating C233, between a redimita(late) female and an ovata (early) male produced progeny that fall into a $1: 1$, redimita (late): ovata (early), ratio in females and a $1: 1$, lineata : ovata (early), ratio in males. That is, the morphs and their development times shown by the parents emerge in the same combinations in the offspring. Since redimita(late) is not expressed in males, the lineata-like males in the progeny were presumably carrying the redimita(late) determinant. Total numbers of ovata and of the other morphs combined would be expected to fall into a 1:1 ratio. In fact the observed ratio of 43:23 differs significantly from this expectation $\left(\chi_{(1)}^{2}=6 \cdot 06,0.02>P>0.01\right)$ and may be due to an ascertainment bias introduced by the removal of ovata, but not other morphs, as juveniles. Mortality during development would lower the relative numbers of spiders scored as adults. The overall heterogeneity of numbers of each morph in the two sexes (assessed by a $2 \times 3$ contingency chi-square test) is highly significant $\left(\chi_{(2)}^{2}=23.02, P<\right.$ $0 \cdot 001)$. Unexpectedly, two late-maturing lineata females were also recovered from the $\mathrm{C} 233$ cage. These may have been contaminants from other cages or it is possible that the female progeny are actually segregating in a $1: 1: 2$ ratio (lineata: redimita (late): ovata) and that, for some reason, the lineata morph is very late to mature in this brood. Seven immature non-ovata female progeny remain unscored but experience suggests that very slow growing spiders seldom survive to maturity and so the phenotype of these individuals will not be known. If they were all lineata at maturity then a reasonable fit to the $1: 1: 2$ ratio would be obtained $(9: 11: 22)$. Mating C235 shows a similar pattern of morphs to C233 except that there is a highly significant deviation from the expected $1: 1$ ratio in males $\left(\chi_{(1)}^{2}=9.80,0.01>P>0.001\right)$ produced by a deficiency of ovata.

Two matings, $\mathrm{C} 236 \mathrm{a}$ and $\mathrm{C} 237$, were between redimita(late) females and redimita(early) males. In both cases, male offspring do not differ significantly from a $1: 1$, lineata : redimita (early), ratio while females segregated for lineata, redimita(early) and redimita(late) in a $1: 2: 1$ ratio in mating C237. Unfortunately, there are too few females from mating C236a to assess in what ratio phenotypes are segregating.

In the brood of C240, males segregate in a $1: 1$, lineata : ovata (early) ratio while females segregate for lineata, redimita(late) and ovata(early). The ovata mother was taken from Nidderdale $\mathrm{Jb}$ in which, at the time of sampling, all but a very small proportion of redimita morphs appeared late and then only in females. (Ovata and a low frequency of redimita(early) 
morphs were introduced into this site by migration from a nearby experimental colony.) Thus, the male with which this female had mated would almost certainly have been lineata-like but carrying the redimita(late) determinant. Numbers are again too small to determine the ratio in which female morphs are segregating.

\section{Discussion}

Data from the breeding experiments reported here clearly demonstrate the polymorphic nature of colour and pattern in E. ovata (cf. Hippa and Oksala, 1979). On no occasion was there any doubt about the morph of parents or their offspring. In a recent countrywide survey of morph frequencies (Oxford, 1983), 99.5 per cent of spiders were categorised as lineata, redimita or ovata; the remainder having a pattern intermediate between ovata and redimita.

Genetically, intermediates act like ovata, as was pointed out above. This identity is powerfully confirmed in all matings involving the ovata morph. Ovata parents, taken from colonies in which intermediates have never been observed, frequently produce ovata progeny with varying amounts of yellow pigment in the central shield i.e., they are intermediates, but these are always clearly distinguishable from redimita. Evidently, some aspect of the laboratory environment prevents the full expression of the pvata pattern. The expression of the ovata phenotype also seems to be influenced by the genetic background, as shown by the offspring of intermediate females caught in the wild (table 1, matings A5f, A7f, A8f, B87, B88). In the progeny of these matings, intermediates segregated which had an even greater amount of yellow in the shield than normal, but even these could not be confused with redimita.

Previous attempts to explain the genetics of pattern and colour in $E$. ovata have involved both single and multi-locus models. Geyer (1967) and Tweedie (1970) suggested a one locus, two allele hypothesis in which ovata and lineata were homozygotes for the two alternative alleles and redimita was the heterozygote. The predictions of this model are clearly at variance with the breeding results (see also Oxford, 1976; Hippa and Oksala, 1979).

Hippa and Oksala (1979) put forward a two locus model in which one locus (red I) coded for morphs in which the red pigment was deposited early in development, and the other (red II) coded for morphs in which red pigment developed late. Thus, at each locus, they postulated a recessive allele producing lineata and a dominant allele producing red pigmented forms. They regarded the traditional separation of redimita and ovata as artificial and proposed that the dominant allele at red II produced a continuous range of phenotypes from redimita through intermediates to ovata. The dominant allele at red I, however, only produced redimita. Since males were never found with the dominant red II allele, Hippa and Oksala supposed that the possession of this allele was lethal in that sex.

In a later paper, Hippa and Oksala (1981) suggested a more elaborate model on the basis of ecological information collected from a number of natural populations near Turku, Finland. Without going into the details of their hypothesis, it is sufficient to point out that it is based on the pooling of heterogeneous data (see, for example, their table 2 of mean sternum lengths in each population, many of which are highly significantly different 
from one another) and the assumption that differences in sternum length and, as a concomitant, egg numbers, are genetically determined.

The data from the present breeding experiments may be summarised as follows.

(i) Red pigment can be deposited early or late in development. If early, the frequencies of morphs are the same in both males and females; if late, pigment appears only in females.

(ii) Where red pigment appears early, lineata, redimita and ovata act as if they are determined by alleles.

(iii) Where red pigment is deposited late, lineata, and redimita appear allelic.

(iv) When broods segregate for both early and late patterns, ratios are consistent with the suggestion that these patterns, and their regulation in development, are determined by alleles.

The following forms, therefore, seem to be allelic; lineata, redimita (early), redimita (late), ovata (early) and, possibly, redimita orange (late). In this country, ovata develops early in all populations examined to date. Hippa and Oksala (1979), however, showed that in northern continental Europe the ovata pattern develops late and then in females only.

A number of hypotheses could be suggested to explain the apparent allelism of colour and pattern and its regulation during development. Three will be considered.

\section{(a) Multiple allele model ( fig. 1a)}

The forms set out above could be true alleles at a single autosomal locus. If this is so, then there must be pairs of redimita and ovata alleles which can be independently regulated to produce the early and late deposition of red pigment. For example, Hippa and Oksala (1979) mention that in some progeny, the redimita pattern appears early in development but is then overlaid in mature females by an ovata pattern. A plausible mechanism by which alleles can be regulated in different ways is not at all obvious.

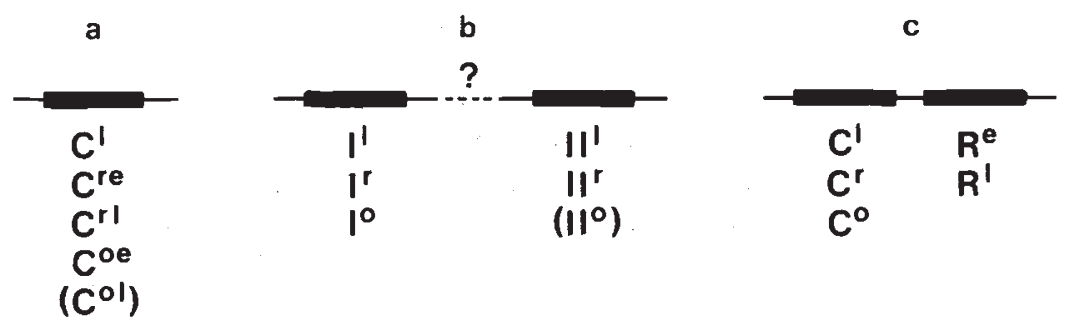

FIG. 1. Three possible models of the genetics of colour and its development in $E$. ovata. In each case the supposed disposition of the loci and the alleles present at each are shown. (a) A single locus with five alleles. Morphs produced by the alleles are shown as superscripts; $1=$ lineata, $\mathrm{re}=$ redimita (early), $\mathrm{rl}=$ redimita (late), oe = ovata (early) and ol = ovata (late). (b) The Hippa and Oksala model of two loci, I for early patterns, II for late patterns. Superscripts $\mathrm{l}=$ lineata, $\mathrm{r}=$ redimita and $\mathrm{o}=$ ovata. (c) $\mathrm{A}$ colour and regulatory locus model. For the colour locus $(C)$, superscripts have the same meaning as under (b) above. At the regulatory locus $(R), \mathrm{e}=$ early development and $\mathrm{l}=$ late development. Alleles in parentheses have not been found in Britain. Further details of these schemes are given in the text. 
One could have the accumulation of some product, slowly in late developing morphs but fast in early developing forms, which needs to reach a threshold before red pigment is produced. Problems then arise in explaining sex limitation and the precision of timing of pigment formation in the late developing patterns. A proportion of females pass through seven, instead of the normal six, instars under laboratory conditions (see also Juberthie, 1954) but even in these, late developing patterns only appear in the last, maturation instar, suggesting an influence of female sex hormones.

\section{(b) Hippa and Oksala (1979) model (fig. 1b)}

The hypothesis proposed by Hippa and Oksala has been outlined above but needs to be extended if it is to accommodate the results of the present breeding experiments. One would have to postulate three alleles at the red $I$ locus coding for early developing patterns, viz., lineata, redimita and ovata, and, in the British Isles, two at the red II locus coding for lineata and redimita. There is, of course, the additional allele for ovata at red II found in continental material. It must be supposed, therefore, that there are pairs of alleles, one at each of the two loci, which code for phenotypically indistinguishable patterns. In this model it is the locus which is differentially activated during development and not particular alleles. Note that the lethality of redimita/ovata at locus red II in males postulated by Hippa and Oksala is not borne out by the breeding results. Indeed, average sex ratios (male:female) from broods containing early or late developing patterns (tables 1 and 2) show just the reverse trend to that expected on their hypothesis viz., $1: 0 \cdot 81$ and $1: 0 \cdot 54$, respectively. The lower ratio of females in table 2 probably results from the fact that females mature more slowly than males and since all individuals included in the table were mature, females may have suffered a higher overall mortality before scoring.

\section{(c) Colour and regulatory loci model (fig. 1c)}

A third hypothesis is that there are two loci involved, one concerned with pattern and colour and the other with the regulation of this colour locus during development. Thus, redimita (early) and redimita (late) would be determined by the same allele at the colour locus but be regulated by alternative alleles at the second locus. If the regulatory locus is called $R$, the two alleles $R^{e}$ and $R^{l}$ would code for early and late pattern development, respectively. In this way the problem of having to postulate two pattern/colour loci each with identical alleles is circumvented. If this model is correct then the lack of recombination in breeding and field data suggest that the colour and regulatory loci are linked. Furthermore, it appears that regulatory alleles are cis-acting only.

In the absence of knowledge about the regulatory alleles present in lineata individuals, linkage can only be inferred. In all laboratory crosses the same combination of red-pigmented morph and its regulation appears in the progeny as was present in the parents. Field observations also suggest close linkage between the two putative loci. For example, sampling at Nidderdale site $\mathrm{AC}$ before and after females reach maturity has shown that all ovata (frequency, 0.03 ) develop red pigment early but that all redimita (frequency, $0 \cdot 21$ ) develop their patterns late (Oxford, unpublished). Since 
redimita (early) is found in the same study area, viability differences are unlikely to be responsible for the lack of this combination.

The observation of individuals in which the redimita pattern appears early and the ovata pattern late (Hippa and Oksala, 1979) suggests that $R$-alleles are only cis-acting. These spiders must have been heterozygous both at the $C$ and $R$ loci. The fact that patterns did not both develop either early or late indicates independence in the regulation of the colour alleles. Since ovata always develops late in Finnish material (Hippa and Oksala, 1979), this model would suggest the genotype $C^{0} R^{l} / C^{r} R^{e}$ for these offspring. Unfortunately, with ovata being top dominant and appearing only in the third or fourth instars in Britain, this effect could not be observed in the present breeding programme. However, cis-acting regulatory alleles are suggested by the fact that parental combinations of colour/regulation are the same as offspring combinations, irrespective of the source of the other parent. For example, a redimita (late) female mated to a lineata male, from a colony in which all red-pigmented forms develop their patterns early, produces late redimita offspring. Conversely, redimita(early) and ovata (early) individuals mated to lineata from a uniformly "late" site produce only early developing patterns. Admittedly, if linkage between the loci is tight there is no reason to expect linkage equilibrium within a colony but the consistency of matings such as these do support the cis-acting hypothesis.

The mechanism by which the regulatory alleles control the colour locus in this model may be as follows. The $R^{e}$ allele allows the expression of its associated colour allele to occur whenever a particular developmental cue is received, usually in the third or fourth instars. $R^{l}$, on the other hand, may be insensitive to this cue and only activates its colour allele in the hormonal environment of a mature female.

All three models explored above could explain the breeding results and are consistent with field observations. The problem of alleles controlling their own regulation would seen to eliminate the first model. Models (b) and (c) are more difficult to differentiate between for, in the majority of crosses, both predict the same phenotype ratios in progeny. This applies in model (b) whether the two loci are linked or unlinked. Matings which could distinguish between model (b), with loci unlinked or loosely linked, and model (c) would be between individuals heterozygous for both red pigment alleles and their regulation and lineata. Half of the ovata offspring from matings $\mathrm{C} 233$ and $\mathrm{C} 235$, for example, may have had the desired combinations of characters. A critical outcome supporting model (c) would be the appearance of a few ovata(late) female recombinants. Since these have not been found in the field or reared at York, their presence could not be attributed to contamination between cages. Unfortunately, all attempts to cross these ovata (and redimita (early) from matings C236a and C237) with lineata have failed. Indeed, since the breeding programme started, very few successful matings have been made between individuals reared from eggs in the laboratory. The ultimate reason for this is not known but the proximate cause is a lack of spermatogenesis in males.

Very tight linkage between the loci postulated in model (b) would make it virtually impossible to decide between it and model (c). On probabilistic grounds, however, model (c) seems slightly more attractive since it does not involve parallel series of alleles at two loci and is consistent with the 
control of gene regulation in other eukaryotes (Paigen, 1979). The differences between the developmental stage at which the ovata pattern appears in the British Isles and in northern Europe could be accounted for by a rare recombination event between the $C$ and $R$ loci.

Finally, there is the question of how, irrespective of the precise genetic control of the polymorphism, alleles can alter not only colour but pattern as well. In $E$. ovata, at least part of the answer seems to be straightforward; a prepattern is present before red pigment deposition begins. Many individuals of the lineata morph show a slightly deeper yellow pigment, or a greyish tinge (resulting from the brown digestive diverticulae showing through the body wall) in the position of the stripes of redimita (noted also by Seligy, 1969). Often the chevrons, which are so obvious in intermediates between redimita and ovata are also discernible (Plate 1e). Thus the elements of the pattern seem to be determined by a locus or loci distinct from that controlling red pigment formation. Given a prepattern, it is not difficult to envisage how the observed phenotypes could be generated by a single colour locus.

In conclusion, breeding studies have shown that the colour/pattern variation in Enoplognatha ovata is genetically determined and that in mature females there is a dominance hierarchy with ovata top dominant and lineata bottom recessive. It has also been demonstrated that the redimita pattern can sometimes be sex limited to females. The complexities of the exact genetic control of pattern and its regulation during development have not been solved and, indeed, their solution would be both difficult and very time consuming given the far from ideal properties of the organism (e.g., long generation time and the inability to set up successful second generation laboratory crosses).

Acknowledgements. I would like to thank Terry Crawford and John Sparrow for supplying musk mallow plants on which the whitefly were cultured and Drosophila food vials, respectively. They also made helpful comments on early drafts of the manuscript. I am also grateful to Stella Linfoot and Richard Pitts who assisted at various times in feeding spiders and to Dick Hunter for taking the photographs. This work was supported in part by a Science Research Council Grant (GR/A55417).

\section{REFERENCES}

BLANKE, R. AND MERKLINGER, F. 1982. Die Variabilität von Zeichnungsmuster und Helligkeit des Abdomens bei Araneus diadematus Clerck und Araneus marmoreus Clerck (Arachnida: Araneae). Z. zool. Syst. Evolut.-forsch., 20, 63-75.

BRISTOWE, W. S. 1931. Notes on the biology of spiders -V. Theridion ovatum, Clerck, its habits and varieties. Ann. Mag. Nat. Hist., 8, 466-469.

GEYER, T. A. 1967. Polymorphism in the spider Theridion ovatum. Nature 213, 314.

HIPPA, H. AND OKSALA, I. 1979. Colour polymorphism of Enoplognatha ovata (Clerck) (Araneae, Theridiidae) in western Europe. Hereditas, 90, 203-212.

HIPPA, H. AND OKSALA, I. 1981. Polymorphism and reproductive strategy of Enoplognatha ovata (Clerck) (Araneae, Theridiidae) in northern Europe. Annls. zool. Fenn., 18, 179190.

JUBERTHIE, C. 1954. Sur les cycles biologiques des araignées. Bull. Soc. d'Hist. Nat. Toulouse, $89,299-318$.

LOCKET, G. H. AND MILLIDGE, A. F. 1951. British spiders 1 , Ray Society, London.

LOCKET, G. H. AND MILlIDGE, A. F. 1953. British spiders II, Ray Society, London.

NAKAHIRA, K. 1977. Genetic polymorphism found in the species "Dolomedes sulfureus L. Koch" (Araneae: Pisauridae). Acta arachnol., 27 (special number), 45-49. 
OXFORD, G. S. 1976. The colour polymorphism in Enoplognatha ovatum (Clerck) (Araneae: Theridiidae)-Temporal stability and spatial variability. Heredity, 36, 369-381.

OXFORD, G. S. 1981. An easily constructed holding device for the examination of live spiders. Bull. Br. arachnol. Soc., 5, 278-279.

OXFORD, G. S. 1983. A countrywide survey of colour morph frequencies in the spider. Enoplognatha ovata (Clerck) (Araneae: Theridiidae). Biol. J. Linn. Soc. (in press).

OXFORD, G. S. AND PITTS, R. J. 1981. A simple, self-maintaining rearing cage for spider broods. Bull. Br. arachnol. Soc., 5, 232-233.

PAIGEN, K. 1979. Genetic factors in developmental regulation. In J. G. Scandalios (ed.), Physiological Genetics, pp. 1-61. Academic Press, London.

SELIGY, V. L. 1969. Biochemical aspects of pigment variation in the spider Enoplognatha ovata (Clerck) (Araneae: Theridiidae). Can. J. Zool., 47, 1103-1105.

SELIGY, V. L. 1971. Postembryonic development of the spider Enoplognatha ovata (Clerck) (Araneae: Theridiidae). Zool. J. Linn. Soc., 50, 21-31.

TWEEDIE, M. W. F. 1970. A case of balanced polymorphism in a spider. Ent. Gazette, 21, 50. 